\title{
Active Promotion of Student's Association Activities Boosts Interest in Learners
}

Miruka Conrad Ondieki*

Kampala International University-Western Campus, Bushenyi-71, Uganda

\section{Introduction}

A students' association has been defined by Wikipedia as "an organization, operated by students at a university, whose membership normally consists only of students". Published literature on students associations or their activities is very scarce to find in journals. Most universities and colleges in the world have students' associations which range in activities from advocating for equal opportunities in the university, advocating for non-discrimination, advocating against sexual assault, advocating for transparency in examination results, among other activities. Most students' associations usually have membership from the current students in the university or former students who are willing to join the association. Membership to the association may be by subscription or automatic by virtue of one being a student in the concerned institution. With a critical role to play in a student's life, the associations are more often recognized by the university authority as administrative entities within the student population. The governing of the associations ranges from a president, vice president, treasurer, communications officer, activities officer, and various class and program representatives. Here, I want to share the achievements and inspirational activities of Kampala International University- Western Campus, Pharmacy Students Association (Uganda).

\section{Organizing Conferences}

The association has actively been organizing conferences since its inception. Most of the conferences are funded by the association itself with some support from the pharmaceutical industries which showcase their products at the conferences. Many students from other universities participate in these conferences and get to learn new ideas in the broad field of pharmacy. The companies showcasing their products at the conferences also get a platform to build new customer bases. In several such conferences, some students get a chance to network with industry and finally yield the opportunity to get internship/industrial placements.

\section{Road Safety Advocacy Campaigns}

The Pharmacy Students' Association of Kampala International University-Western Campus has organized multiple road safety campaigns throughout its existence. In such campaigns, it engages in activities such as road safety awareness, painting of zebra crossings around schools and universities, erection of road humps, engaging the drivers in road safety training among other activities (Figure 1).

\section{Blood Donation Camps}

There are multiple such camps which have been organized by the association. The resulting blood donated is usually given to the blood banks of surrounding hospitals, where it is used in blood transfusion exercises. In such camps, other students, staffs and the general public are encouraged to donate blood, with the slogan "Donate blood, Save lives" dominating the event (Figure 2).

\section{Repainting and Labeling of the Pharmacy Block}

This was done after consultation with the university management. The labelling of the block made it stand out uniquely from the other adjacent blocks in the campus (Figure 3). More so, there is a sign post erected near the block which welcomes guests to the pharmacy block.

\section{Printing of Promotional Materials}

The association has actively been involved in printing its promotional materials for the general public. These include calendars, T-shirts, short-hand notebooks, caps, among others (Figures 4 and 5). These are given to staffs and students within the university at a small fee. The proceeds from the sales are in turn used to partially finance the activities of the association. When a person visits any office in the university, it is very likely that they will spot an association calendar on the wall. This serves to promote awareness of the association.

\section{Positive Effects of the Association's Activities on Learners}

There have been many positive changes that have occurred in the pharmacy students due to active participation in the association's activities. Many students have learnt teamwork skills, leadership

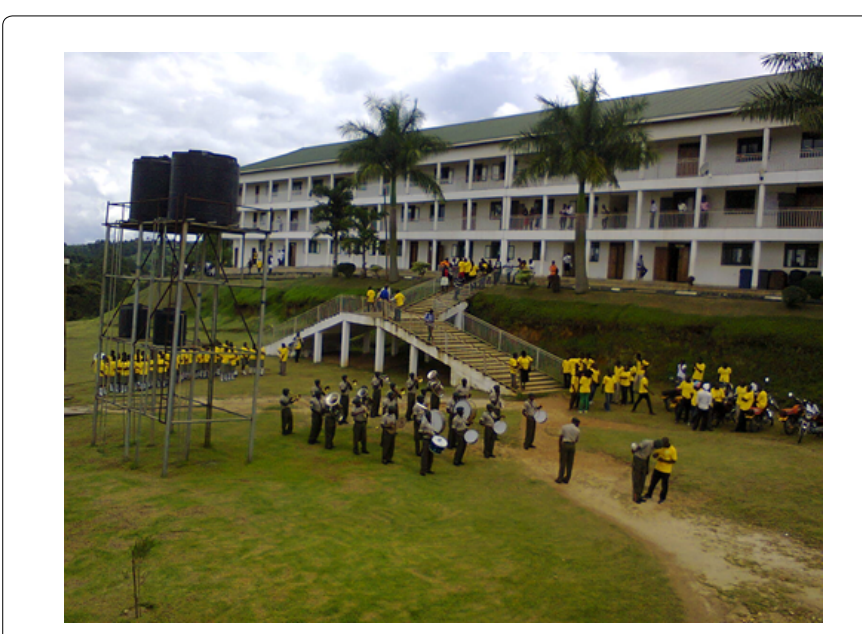

Figure 1: Pharmacy students association preparing for a road safety campaign.

*Corresponding author: Miruka Conrad Ondieki, Kampala International University-Western Campus, Bushenyi-71, Uganda, Tel: +256777410403; E-mail: conradmiruka@yahoo.com

Received December 19, 2014; Accepted June 25, 2015; Published June 27, 2015

Citation: Ondieki MC (2015) Active Promotion of Student's Association Activities Boosts Interest in Learners. J Health Edu Res Dev S1: 004. doi:10.4172/2380-5439. S1-004

Copyright: (C) 2015 Ondieki MC. This is an open-access article distributed under the terms of the Creative Commons Attribution License, which permits unrestricted use, distribution, and reproduction in any medium, provided the original author and source are credited. 
Citation: Ondieki MC (2015) Active Promotion of Student's Association Activities Boosts Interest in Learners. J Health Edu Res Dev S1: 004. doi:10.4172/2380-5439.S1-004

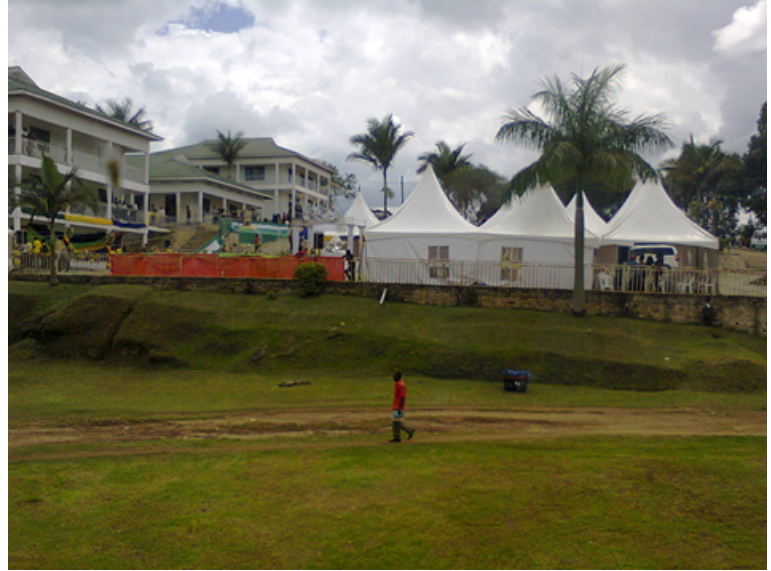

Figure 2: A blood donation camp organized by the Pharmacy Students Association.

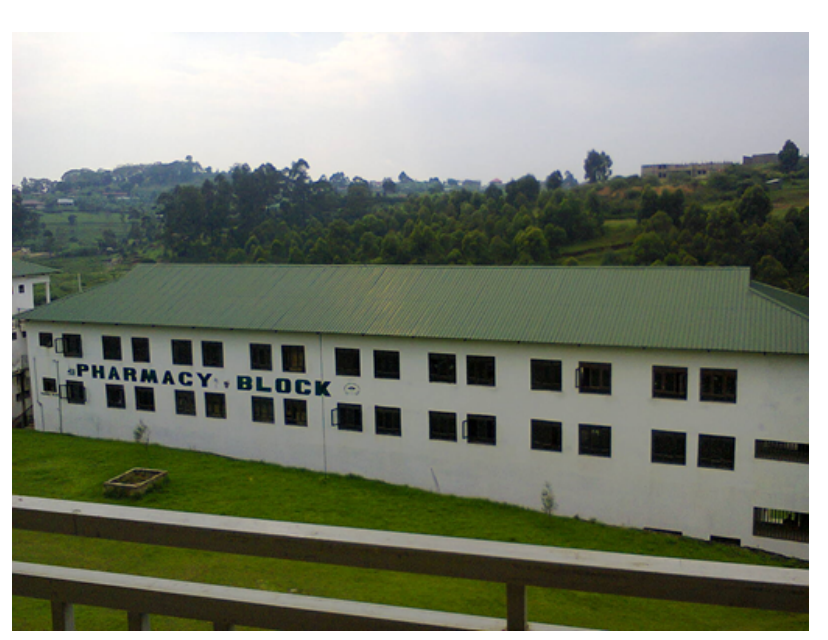

Figure 3: Repainted and labelled pharmacy block.

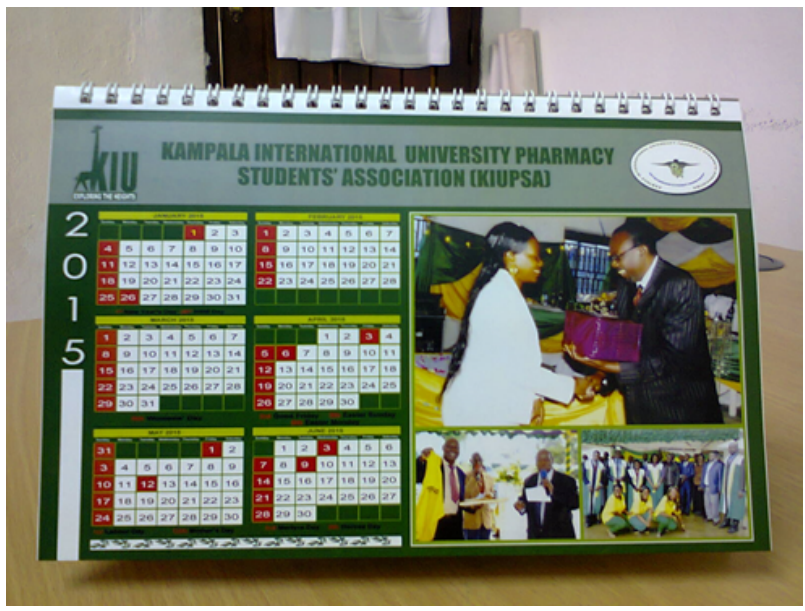

Figure 4: A 2015 calendar made by the association.

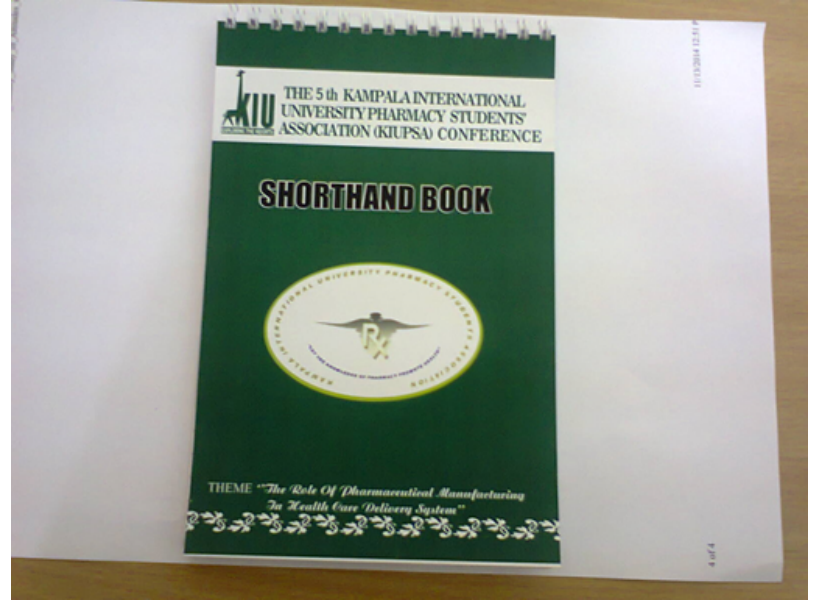

Figure 5: A short-hand notebook made by the association promoting a conference.

skills, improved time management skills, networking skills, better communications skills, public speaking skills, persuasion skills among others. It is hoped that these set of skills which have been learnt from active participation in the association's activities will be useful to the students once they leave campus and transform into working citizens. Some of these same set of skills are highly valued by employers when they are recruiting individuals to join their teams.

\section{General High Recognition of the Association within the Campus}

The association has had a relatively high recognition by the entire campus community. Students enrolled in other associations have been repeatedly heard saying, "I wish our association was like the Pharmacy Students Association". Staff's recognition of the association has also not been left behind. In fact, some staffs have been praising the association in their social network pages.

\section{Conclusion}

In light of the aforementioned benefits of active promotion of students association's activities, it is hoped that more can be done to further improve the same. The other associations in other universities can learn a lesson from these benefits. University management committees can actively engage in supporting such associations since some of the skills learnt in the association are not taught in mainstream curricula.
This article was originally published in a special issue, Etiology of Diseases, Nutrition and Human Learning handled by Editor(s). Dr. Miruka Conrad Ondieki, Kampala International University 